\title{
Wind Power potential in Kigali and Western provinces of Rwanda

\section{Otieno Fredrick Onyango ${ }^{1}$, Sibomana Gaston ${ }^{2}$, Elie Kabende ${ }^{3}$, Felix Nkunda ${ }^{4}$, Jared Hera Ndeda ${ }^{5}$}

${ }^{1}$ Senior Lecturer, Department of Mathematics and Physical Sciences, Maasai Mara University, Kenya

${ }^{2,3,4}$ Department of Applied Physics, Kigali Institute of Science and Technology, Rwanda

${ }^{5}$ Senior Lecturer, Department of Physics, Jomo Kenyatta University of Agriculture \& Technology, Kenya

\begin{abstract}
Wind speed and wind direction are the most important characteristics for assessing wind energy potential of a location using suitable probability density functions. In this investigation, a hybrid-Weibull probability density function was used to analyze data from Kigali, Gisenyi, and Kamembe stations. Kigali is located in the Eastern side of Rwanda while Gisenyi and Kamembe are to the West. Onsite hourly wind speed and wind direction data for the year 2007 were analyzed using Matlab programmes. The annual mean wind speed for Kigali, Gisenyi, and Kamembe sites were determined as $2.36 \mathrm{~m} / \mathrm{s}, 2.95 \mathrm{~m} / \mathrm{s}$ and $2.97 \mathrm{~m} / \mathrm{s}$ respectively, while corresponding dominant wind directions for the stations were $320^{\circ}, 180^{\circ}$ and $150^{\circ}$ respectively. The annual wind power density of Kigali was found to be $13.7 \mathrm{~W} / \mathrm{m}^{2}$, while the power densities for Gisenyi and Kamembe were determined as $18.4 \mathrm{~W} / \mathrm{m}^{2}$ and $24.4 \mathrm{~W} / \mathrm{m}^{2}$. It is clear, the investigated regions are dominated by low wind speeds thus are suitable for small-scale wind power generation especially at Kamembe site.
\end{abstract}

Keywords: Probability density function, Wind power density, Wind speed
This article is is licensed under a Creative Commons AttributionNonCommercial 4.0 International License.

Attribution-NonCommercial (CC BY-NC) license lets others remix, tweak, and build upon work non-commercially, and although the new works must also acknowledge \& be noncommercial.

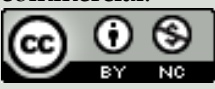

How to Cite:

Onyango OF, Gaston S, Kabende E, Nkunda F, Ndeda JH. Wind Power potential in Kigali and Western provinces of Rwanda Asia Pacific Journal of Energy and

Environment. 2014;1(3):189-199.

Source of Support: SFAR

Conflict of Interest: Non Declared

\section{INTRODUCTION}

Rwanda is a landlocked country in central Africa with a surface area of $26,338 \mathrm{~km}^{2}$ and located between 20:00 Latitude South and 300:00 Longitude East. It borders Tanzania to the east, Democratic republic of Congo to the West, Uganda to the North and Burundi to the South (figure 1). Energy supply in the country is mainly from hydro and thermal sources where the former accounts for $26.74 \mathrm{MW}$ and the latter contributes $29.57 \mathrm{MW}$ against a skyrocketing national demand. Available electricity is therefore insufficient to meet both domestic and industrial needs required for sustainable economic development. The demand for electricity, that continues to rise every year, has necessitated a projected expansion from the current 69MW to 130MW by the year 2015 (Ministry of Infrastructure, 
2014). The expansions would mainly be in hydro and thermal sources that have since attracted interest from development partners and investors probably because feasibility data were promising. Currently, the primary energy balance in Rwanda consists of Biomass at 93.1\%, Fuel 6\%, and electricity 0.9\% (Bonfils Safari, 2010). In the biomass category, wood fuel dominates at $80.4 \%$, charcoal $1.9 \%$ while agricultural waste and peat occupy $10.8 \%$. On the other hand, electricity component is mainly hydro-based derived from both local and regional sources (Safari, 2010). Interestingly, only a tiny contribution of electrical energy comes from solar power estimated at $0.25 \mathrm{MW}$ although there is an abundant solar radiation as indicated by the global annual daily mean of $5.2 \mathrm{kWhm}^{-2}$. This reveals that potential of solar power exists but is largely unexploited.

Currently only about $6 \%$ of the Rwandan population have access to electricity and there are plans to boost this to about $16 \%$ by the year 2017 through various initiatives under Electricity Access Roll out Programme (EARP) (Ministry of Infrastructure, 2014). The initiative (EARP) is divided into two parts, grid and non-grid components. Grid component, under Rwanda Electricity Corporation (RECO) deals with distribution and connections to the national grid, where the major sources of electricity are thermal and hydroelectricity. The non-grid component, under the ministry of Infrastructure (MININFRA) covers electrification of social institutions that are at least $5 \mathrm{~km}$ away from the national grid network. Here, the targeted source of power is solar energy and micro hydropower. In both cases, wind does not feature as a possible source of energy due to insufficient information about its potential at various locations (Ministry of Infrastructure, 2014). Indeed, MININFRA commissioned a feasibility study in 2009 to generate a wind atlas map of Rwanda in order to identify potential sites for possible wind energy exploitation. Electricity is derived from wind using a wind turbine. Being a renewable energy source, wind energy is the fastest growing with the global installed capacity now surpassing 93GW (Dinler, 2009). This is due to improved technology in the wind-energy conversion systems that can transform $50 \%$ of wind power into mechanical energy (Ilkilic \& Turkbay, 2010). As such, it is an economically attractive source of energy compared to the dwindling fossil fuel reserves. Assessment of wind power potential of a site is done by

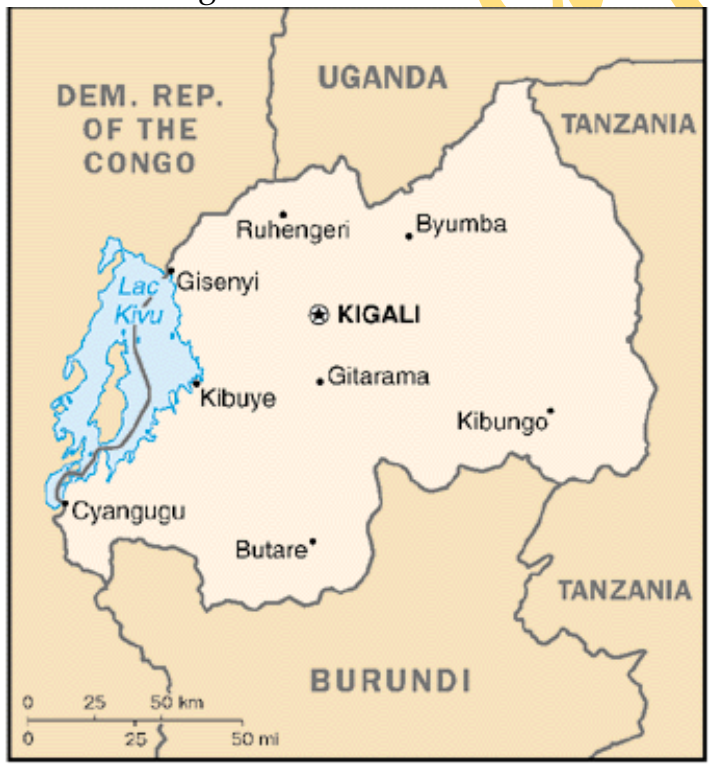

Asian Business Consortium | APJEE various methods (Bilgil \& Sahin, 2009); (Carta, et al., 2009); (Gong \& Jing, 2010); (Seyit, et al., 2010) to estimate possible magnitudes of wind power densities in an area. The methods use probability density functions that describe the distribution of wind speeds since wind is a random variable. The kinetic energy of wind generates electricity up to a maximum efficiency of the conversion system and depends on optimal selection of wind speed distribution as one of the parameters.

Figure 1: Map of Rwanda (Wikipedia, n.d.)

The commonly used and widely accepted distribution function to describe wind speeds in many regions of the world is the two-parameter 
Weibull distribution (Himri, et al., 2010). However, it does not represent all wind regimes in every region of the world. In such cases, alternative distributions are required that suit specific wind regimes (Khan \& Shahidehpour, 2009).

\section{WIND DATA}

The historical wind data used in this study are from Kamembe and Gisenyi stations, both in the Western province of Rwanda, while Kanombe station is in Kigali province. Kamembe is the airport in Cyangugu at the shores of Lake Kivu as shown in figure 1. Meteorological department (Meteo) Rwanda that collects and archives all weather-related information of the country manages the stations. The hourly wind speed and wind direction data were recorded at anemometer height of $10 \mathrm{~m}$ above ground. Table I gives the measuring year of the data, geographical coordinates, and altitude of the stations.

Table I: Geographic parameters of the site

\begin{tabular}{|l|l|l|c|c|c|}
\hline \multicolumn{1}{|c|}{ Station } & \multicolumn{1}{|c|}{ latitude } & \multicolumn{1}{|c|}{ Longitude } & $\begin{array}{c}\text { Altitude } \\
(\mathrm{m})\end{array}$ & $\begin{array}{c}\text { Measuring } \\
\text { year }\end{array}$ & $\begin{array}{c}\text { Anemometer } \\
\text { height }(\mathrm{m})\end{array}$ \\
\hline Kamembe & $2^{\circ} 28^{\prime} 0^{\prime \prime} \mathrm{S}$ & $28^{\circ} 55^{\prime} 0^{\prime \prime} \mathrm{E}$ & 1491 & 2007 & 10 \\
\hline Gisenyi & $01^{\circ} 40^{\prime} 37.93^{\prime \prime} \mathrm{S}$ & $02^{\circ} 15^{\prime} 31.95^{\prime \prime} \mathrm{E}$ & 1549 & 2007 & 10 \\
\hline Kanombe & $1^{0} 57^{\prime} 55.33^{\prime \prime} \mathrm{S}$ & $30^{\circ} 08^{\prime} 05.18^{\prime \prime} \mathrm{E}$ & 1494 & 2007 & 10 \\
\hline
\end{tabular}

\section{MATERIALS AND METHOD}

\section{Hybrid-Weibull distribution function}

Probability density functions (PDFs) are important in wind studies to estimate the power of a given wind speed which is then compared with the measured probabilities found by getting the ratio of the frequency of a given speed to the total frequency of speeds occurring in a location. The probability density function that has wide appeal as the standard function for wind speed modelling is the Weibull distribution (equation 1), but it is most appropriate for regions with negligible occurrence of null wind speeds. If one cannot ignore the presence of null wind speeds then appropriate modifications to Weibull distribution is necessary. One such modification is the Hybrid Weibull distribution given in equation 2 with $\phi$ representing the distribution parameters $k$ and $c$, while $\theta_{\mathrm{o}}$ is the probability of null wind speeds. In this paper, the hybrid Weibull distribution was used for the analysis of wind power density.

The hybrid Weibull distribution is well defined (Carta, et al., 2009). Generally, the Weibull probability density function of a random variable $v$ is given in equation 1 where $\mathrm{k}$ is a shape parameter while $\mathrm{c}$ is a scale parameter. Both of these parameters are functions of mean wind speed and standard deviation as in equation 3 and 4 respectively.

$$
f_{w}(v)=\left(\frac{k}{c}\right)\left(\frac{v}{c}\right)^{k-1} \exp \left[-\left(\frac{v}{c}\right)^{k}\right]
$$

Hybrid Weibull distribution

$$
\begin{gathered}
h\left(v, \phi, \theta_{o}\right)=\theta_{0} \delta(v)+\left(1-\theta_{o}\right) f_{w}(v, \phi) \\
\text { where } \delta(v)=\left\{\begin{array}{l}
1, \text { if } v=0 \\
0, \text { if } v \neq 0
\end{array}\right. \\
k=\left(\frac{\sigma}{v_{m}}\right)^{-1.086 \quad(1 \leq k \leq 10)}
\end{gathered}
$$




$$
c=\frac{v_{m}}{\Gamma\left(1+\frac{1}{k}\right)}
$$

Where $\mathcal{V}_{m}$ the mean wind speed is defined in equation 5 and $\sigma$ is standard deviation as in equation 6 . The symbol $\Gamma()$ represents a gamma function of the bracketed term defined for $n$ hours in equation 7 .

$$
\begin{aligned}
& v_{m}=\frac{1}{n}\left[\sum_{i=1}^{n} v_{i}\right] \\
& \sigma=\left[\frac{1}{n-1} \sum_{i=1}^{n}\left(v_{i}-v_{m}\right)^{2}\right]^{\frac{1}{2}} \\
& \Gamma(n)=\int_{0}^{\infty} x^{n-1} e^{-x} d x
\end{aligned}
$$

The hybrid Weibull cumulative distribution function in equation 9 is also defined from the Weibull cumulative distribution function of equation 8 .

$F_{w}(v)=1-\exp \left[-\left(\frac{v}{c}\right)^{k}\right]$

$H\left(v, \emptyset, \theta_{o}\right)=\left\{\begin{array}{r}\theta_{0}+\left(1-\theta_{o}\right) F_{w}(v, \emptyset), \text { if } v \geq 0 \\ 0, \text { if } v<0\end{array}\right.$

Wind power density per unit area $P_{w}$ was calculated from equation 10

$P_{w}=\frac{1}{2} \rho \int_{0}^{\infty} v^{3} h\left(v, \phi, \theta_{o}\right) d v$

Where $\rho$ is the density of the wind for each station.

\section{The MATLAB PROGRAM}

The program routines for analysis of measured data have Matlab as the main calculation engine. It consists of four main subroutines with the first one having to sort and import the measured wind speed and wind direction data available in excel tables, into Matlab environment in a predetermined format for suitable processing. The frequency distribution and associated statistics of the measured data such as the mean and standard deviation are the output of a statistical subroutine that uses most of the Matlab's in-built mathematical functions. Resulting frequency distribution table from 'statistics' subroutine establishes the dominant direction of wind flow and the most frequent wind speeds. Secondary information generated from statistical calculations of the data are input into a 'parameters' subroutine that determine Weibull parameters and also calculates the probability density functions using equation 2. Finally, the power density estimates emerge from the 'power density' subroutine that outputs all the required graphical illustrations and comparisons given in the bar graphs with the help of equation 10. 


\section{Performance Analysis}

There are various methods used to analyze convergence between measured data and results that are due to a mathematical model. Performance analysis of results obtained from the Hybrid-Weibull distribution was done using the mean absolute percentage error (MAPE) given in equation 11. The coefficient of correlation between the measured and estimated data was also determined using equation 12.

$M A P E=\frac{1}{t} \sum_{j=1}^{t} a b s\left(\frac{e_{j}-m_{j}}{e_{j}}\right) \times 100$

$R=\frac{\overline{m \cdot e}-\bar{m} \cdot \bar{e}}{\sqrt{\left\{\overline{m^{2}}-(\bar{m})^{2}\right\} \cdot\left\{\bar{e}^{2}-(\bar{e})^{2}\right\}}}$

Where $\mathrm{m}$ is the measured wind speed data; $\mathrm{e}$ is the estimated data; $\mathrm{t}$ is the total number of hours; $\bar{e}$ is the mean of estimated data; $\bar{m}$ is the mean of measured data; $\overline{m . e}$ is the mean of product of measured and estimated data.

\section{RESULTS AND Discussions}

\section{DATA ANALYSIS}

Before installation of a wind turbine, it is important to know its proper orientation beforehand so that conversion of available wind speeds into mechanical energy is optimized. Similarly, the choice of a target installation site of a wind turbine is guided by acceptable criterion that yields maximum power. To aid in the choice of orientation and location of wind turbine two factors are frequently used. These are magnitude and probability of wind speed distributions in the various directions and the most dominant wind direction (Carrillo, et al., 2010). Topography affects wind speed and wind direction (Yohana, et al., 2009) as such correctional procedures are frequently used to establish wind speed profiles. In this investigation the effect of terrain on wind speeds has been assumed because in the vicinity of the measurement instruments of all the stations there were no obstacles that could significantly influence the wind speeds. Results presented in figure 2 give the dominant wind directions for Kanombe, Gisenyi, and Kamembe stations. However, it does not take care of the effects of topography in the distribution of wind speeds. The dominant direction is the direction which has the highest frequency. From the charts, the wind direction at Kamembe, Gisenyi and Kamembe were $320^{\circ}, 180^{\circ}$ and $150^{\circ}$ respectively, although on average the prevalent wind direction are the same in all stations. In figure 3 variation of diurnal wind speeds for the stations are given. It is evident that the speeds range from $0.73 \mathrm{~m} / \mathrm{s}$ to $3.45 \mathrm{~m} / \mathrm{s}$ with the minimum occurring in the morning hours while the maximum occurs in the afternoon hours. Since daytime data was available from $6 \mathrm{am}$ to $6 \mathrm{pm}$ for the investigated stations, by inference it can be said that higher wind speeds are prevalent during daytime while at night lower wind speeds dominate perhaps due to higher solar intensity that occurs during the day. The claim is supported by the general decline of wind speeds for all stations from 6am until 8am when the sun's intensity start to increase. The highest diurnal wind speed of the three stations occurs at Kamembe where the speeds range between $1.22 \mathrm{~m} / \mathrm{s}$ and $3.45 \mathrm{~m} / \mathrm{s}$. Largely, the speeds are low for adequate generation of wind power given that modern wind energy conversion systems start to generate power at a cut-in-speed of 3m/s (Himri, et al., 2010). However, for small turbines the wind speeds could just be sufficient to provide electric power to domestic and small-scale enterprises since there is no wind turbine currently installed in 
the regions. The lowest diurnal wind speeds are at Gisenyi and Kanombe stations at a mean of $0.73 \mathrm{~m} / \mathrm{s}$ and $0.96 \mathrm{~m} / \mathrm{s}$ respectively.

Adequate use of available wind energy on a site requires sufficient information about wind characteristics that include level and regularity of wind speeds. The distribution of wind speeds is useful in the design of wind farms, power generators, and agricultural applications like irrigation (Gungor \& Eskin, 2008). In table II, the monthly and annual mean wind speed $v_{m}$ and standard deviation $\sigma$ for the stations are shown which were calculated from measured data. It is apparent that monthly mean wind speeds among the stations range between $2.18 \mathrm{~m} / \mathrm{s}$ and $3.57 \mathrm{~m} / \mathrm{s}$ with the lowest monthly mean wind speed of $2.18 \mathrm{~m} / \mathrm{s}$ reported in February at Kanombe station while the highest speed $(3.57 \mathrm{~m} / \mathrm{s})$ occurs at Kamembe in the months of July and August. The table reveals that Kamembe has higher wind speeds with highest variability compared to speeds in Gisenyi and Kanombe stations. The standard deviation vary from a low of $1.13 \mathrm{~m} / \mathrm{s}$ in Gisenyi to a high of $1.58 \mathrm{~m} / \mathrm{s}$ in Kamembe. The Weibull parameters are shown in table III where the annual value of $\mathrm{k}$ appears in the range $1.82 \leq k \leq 2.83$ and that of the scale parameter c varies between $2.65 \mathrm{~m} / \mathrm{s}$ and $3.35 \mathrm{~m} / \mathrm{s}$.
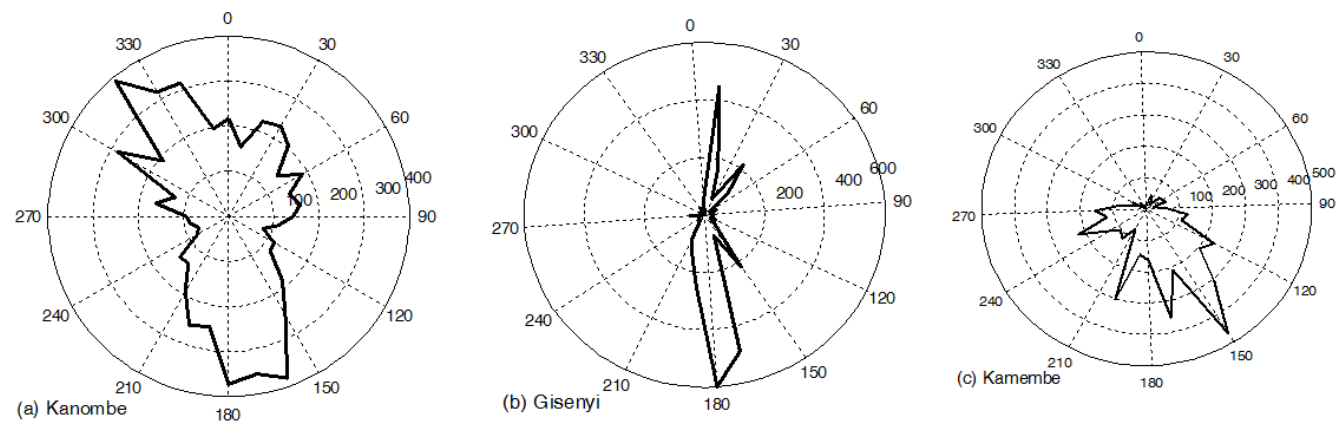

Figure 2: Wind direction frequency distribution for the stations

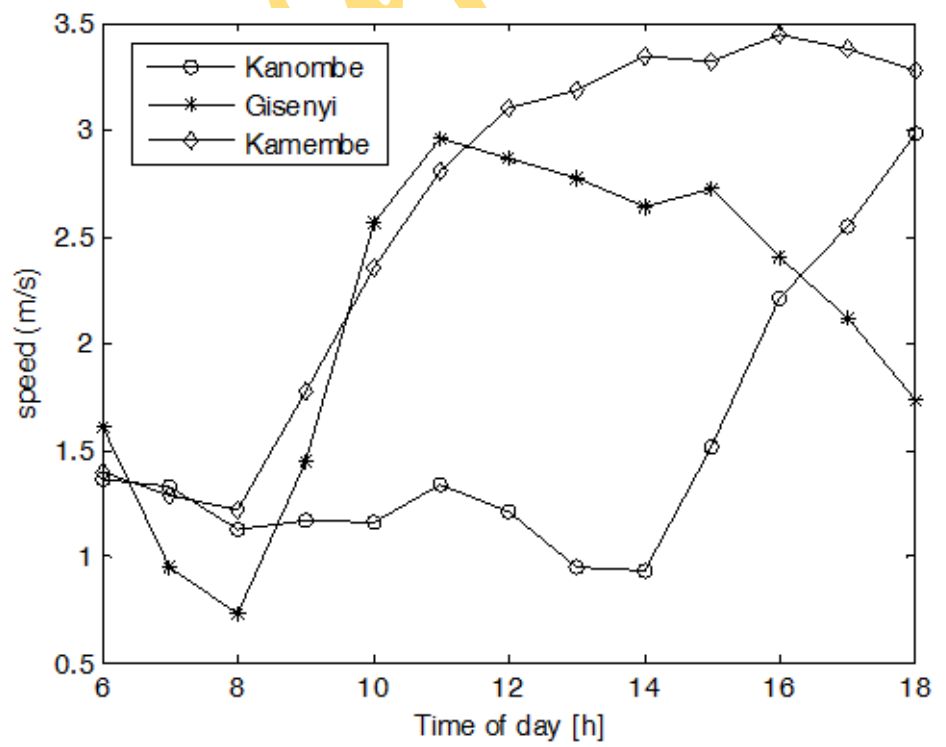

Figure 3: Mean hourly variation of wind speed 
Table II: Monthly and annual mean wind speeds and standard deviations for the investigated stations

\begin{tabular}{|c|c|c|c|c|c|c|c|c|c|c|c|c|c|c|}
\hline Station & Parameters & Jan & Feb & Mar & April & May & June & July & Aug & Sep & Oct & Nov & Dec & Annual \\
\hline Kanombe & Vm $(\mathrm{m} / \mathrm{s})$ & 2.25 & 2.18 & 2.35 & 2.33 & 2.39 & 2.34 & 2.41 & 2.42 & 2.38 & 2.47 & 2.31 & 2.42 & 2.36 \\
& $\sigma(\mathrm{m} / \mathrm{s})$ & 1.26 & 1.29 & 1.20 & 1.40 & 1.74 & 1.54 & 1.35 & 1.35 & 1.22 & 1.28 & 1.35 & 1.25 & 1.36 \\
Gisenyi & Vm $(\mathrm{m} / \mathrm{s})$ & 3.25 & 2.94 & 3.07 & 3.01 & 2.97 & 2.78 & 2.90 & 3.00 & 3.02 & 2.95 & 2.75 & 2.69 & 2.95 \\
& $\sigma(\mathrm{m} / \mathrm{s})$ & 1.25 & 1.19 & 1.29 & 1.00 & 1.03 & 0.91 & 1.37 & 1.31 & 0.89 & 1.20 & 0.92 & 0.85 & 1.13 \\
Kamembe & Vm $(\mathrm{m} / \mathrm{s})$ & 2.35 & 2.56 & 2.68 & 2.83 & 2.85 & 3.34 & 3.57 & 3.57 & 2.96 & 2.86 & 2.83 & 3.09 & 2.97 \\
& $\sigma(\mathrm{m} / \mathrm{s})$ & 1.10 & 1.19 & 1.25 & 1.54 & 1.66 & 1.80 & 1.99 & 1.96 & 1.32 & 1.24 & 1.30 & 1.62 & 1.58 \\
\hline
\end{tabular}

Table III: Monthly and Annual Weibul parameters (shape k, and scale, c) for the investigated stations

\begin{tabular}{|c|c|c|c|c|c|c|c|c|c|c|c|c|c|c|}
\hline Station & Parameters & Jan & Feb & Mar & April & May & June & July & Aug & Sep & Oct & Nov & Dec & Annual \\
\hline Kanombe & $\mathrm{k}$ & 1.88 & 1.76 & 2.07 & 1.74 & 1.42 & 1.58 & 1.87 & 1.88 & 2.07 & 2.05 & 1.79 & 2.04 & 1.82 \\
& $\mathrm{c}(\mathrm{m} / \mathrm{s})$ & 2.53 & 2.45 & 2.65 & 2.62 & 2.63 & 2.61 & 2.72 & 2.73 & 2.68 & 2.79 & 2.59 & 2.73 & 2.65 \\
Gisenyi & $\mathrm{k}$ & 2.82 & 2.67 & 2.56 & 3.30 & 3.17 & 3.35 & 2.26 & 2.46 & 3.79 & 2.64 & 3.30 & 3.51 & 2.83 \\
& $\mathrm{c}(\mathrm{m} / \mathrm{s})$ & 3.65 & 3.31 & 3.46 & 3.35 & 3.32 & 3.09 & 3.27 & 3.38 & 3.34 & 3.32 & 3.06 & 2.99 & 3.31 \\
Kamembe & $\mathrm{k}$ & 2.28 & 2.30 & 2.30 & 1.94 & 1.79 & 1.96 & 1.88 & 1.92 & 2.41 & 2.47 & 2.33 & 2.01 & 1.99 \\
& $\mathrm{c}(\mathrm{m} / \mathrm{s})$ & 2.65 & 2.88 & 3.02 & 3.19 & 3.21 & 3.77 & 4.02 & 4.03 & 3.34 & 3.22 & 3.19 & 3.48 & 3.35 \\
\hline
\end{tabular}

\section{PROBABILITY DENSITY FUNCTIONS}

The probability density distributions for wind speed are given in figures 4-6 while cumulative probability distribution for the stations are in figure 7. A probability density distribution of wind speeds in a given site is important in predicting the daily energy generating capacity of a wind turbine in that the period for which a power plant would be in and out of production is foretold. It also provides information on how often the rated output of a turbine would be achieved, besides telling the range of most frequent wind speeds read from suitable positions on the distribution curve. From the distribution curves, we see that the duration of the most frequent wind speeds according to the hybrid Weibul distribution model is approximately the same across all stations at about $24 \%$ of the time even though the speed level varies. Again higher speeds are at Kamembe region although they occur less frequently compared to Gisenyi and Kanombe stations.

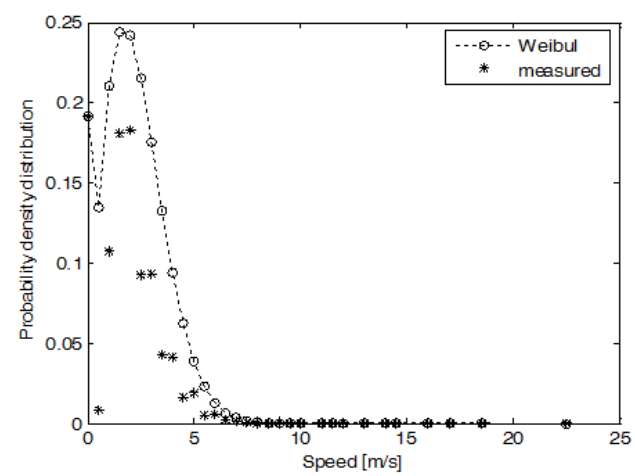

Figure 4: Wind speed frequency distribution for Kanombe station

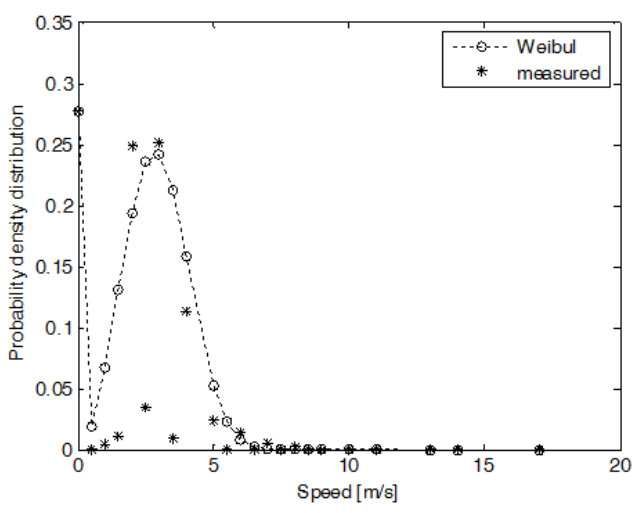

Figure 5: Wind speed frequency distribution for Gisenyi station

It is clear from the curves that the model exaggerates the duration of the most frequent wind speeds in Kanombe and underestimates the same in Gisenyi and Kamembe stations probably due to high frequencies of null wind speeds. This would be a subject of future 
investigations. Otherwise, the measured distribution puts almost at par the duration of occurrence of nonzero most frequent wind speeds in Gisenyi and Kamembe stations. In figure 7, it is apparent that hourly wind speeds are higher in Kamembe followed by Gisenyi with Kanombe having the lowest hourly wind speeds of them all. Kamembe therefore offers better prospects for wind energy generation.

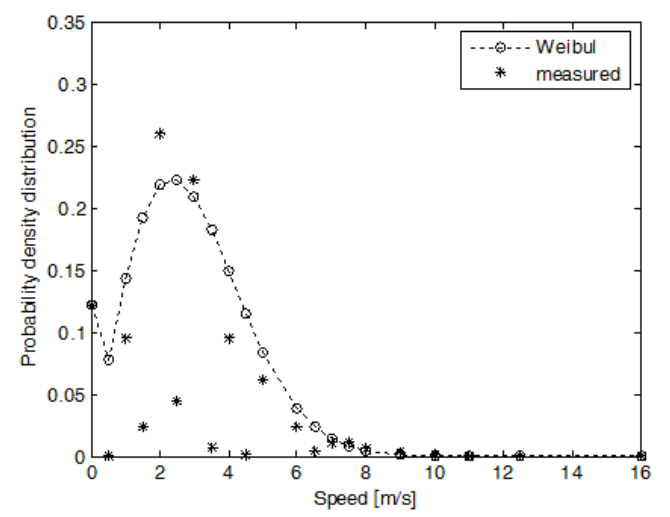

Figure 6: Wind speed frequency distribution for Kamembe station

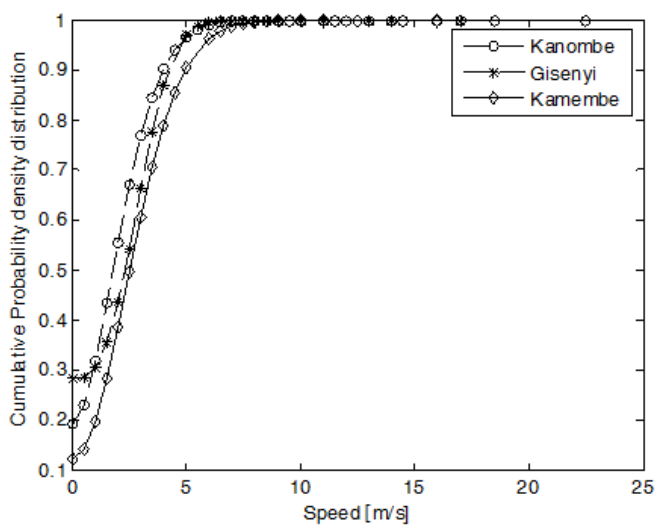

Figure 7: Cumulative distribution function

\section{POWER DENSITY DISTRIBUTIONS}

The bar graphs in figure 8-11 were prepared from Weibull and measured data. They present monthly and annual power density variations in each station and clearly reveal that the hybrid-Weibull model overestimates the actual power densities. It is clear that Kamembe has the highest power densities throughout the year except in the first and third quarters of the year where on average Gisenyi has better prospects. Interestingly, Gisenyi has higher power densities in the first quarter of the year than Kanombe and Kamembe (fig.11), the months it exhibits superior wind speeds than Kamembe station. However, Kamembe records the highest power density of $46 \mathrm{~W} / \mathrm{m}^{2}$ in the month of July, while the

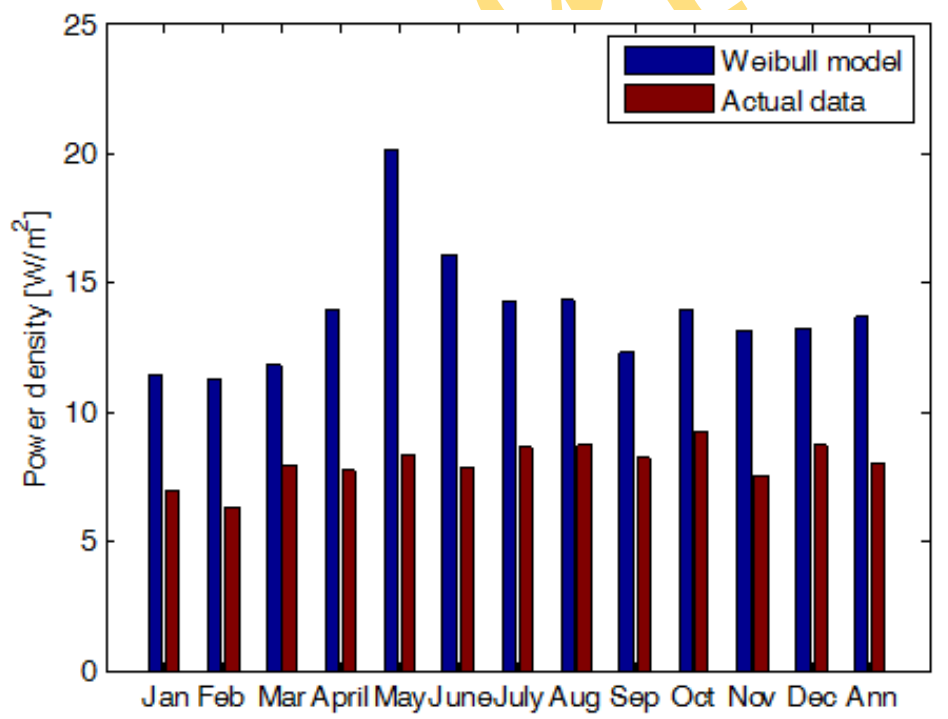
lowest power density of $12 \mathrm{~W} / \mathrm{m}^{2}$ occurs in Kanombe in the month of February. The highest power in Kamembe corresponds to a monthly speed of $3.57 \mathrm{~m} / \mathrm{s}$ available only in $22 \%$ of the one-year period. In overall, Kamembe has the greatest wind power potential than other sites as given by its annual power density of about $24.9 \mathrm{~W} / \mathrm{m}^{2}$.

Figure 8: Monthly and annual Power density variation for Kanombe 
Performance values of the hybrid Weibull model using MAPE and coefficient of correlation R, are given in table IV. It is observed that the values differ across the stations with the best value determined in Gisenyi station, which also gives the best coefficient of correlation at 0.773 . From the performance results, it is necessary to test other models since the Weibull hybrid model appears not to yield best coefficient of correlation values.

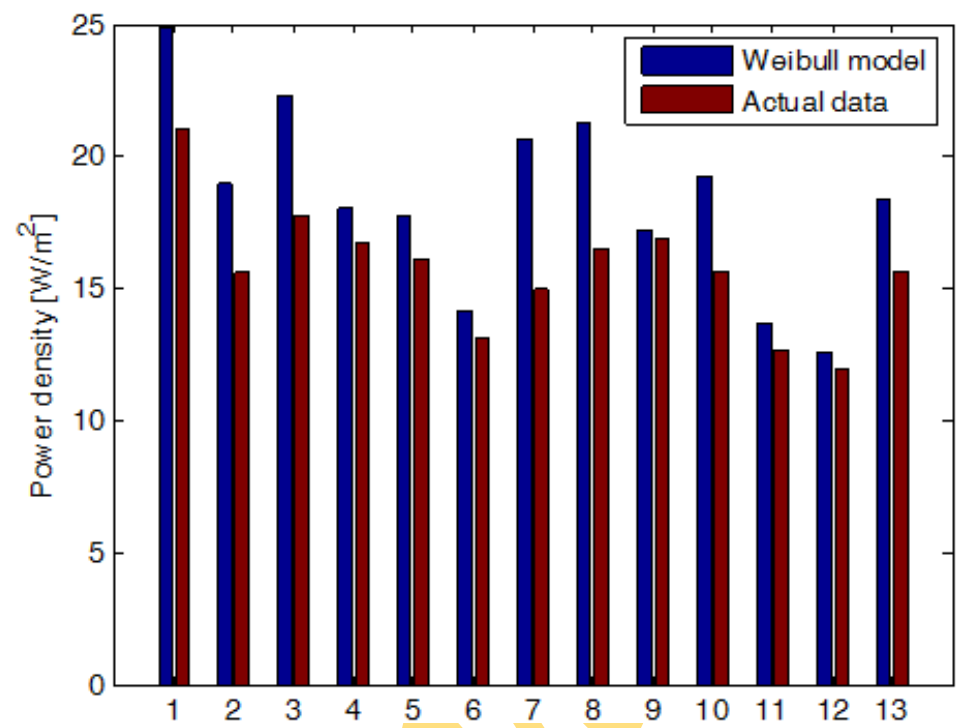

Figure 9: Monthly and annual Power density variation for Gisenyi

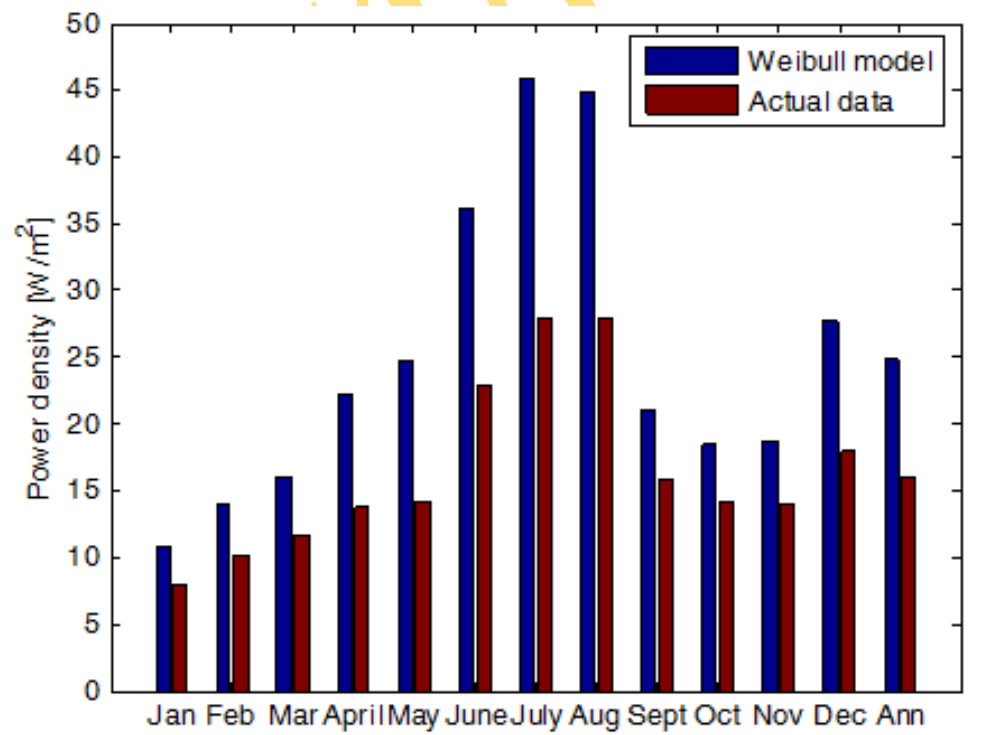

Figure 10: Monthly and annual Power density variation for Kamembe 


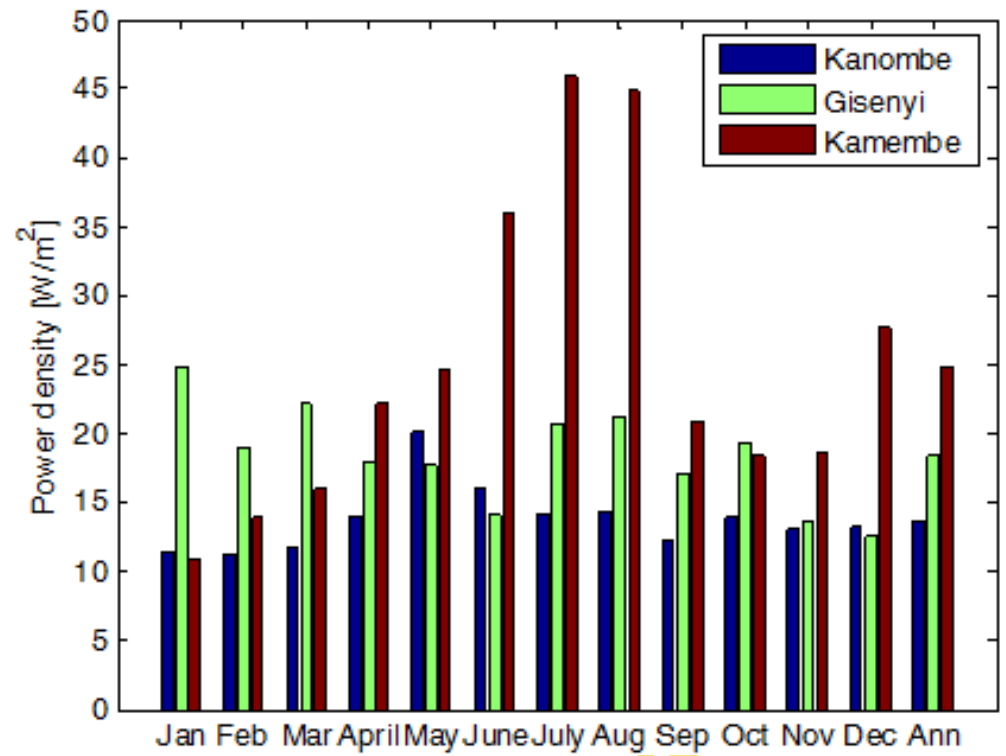

Figure 11: Comparison of monthly and annual power density variation between the three stations

Table IV: Performance values

\begin{tabular}{|l|c|c|}
\hline Station & MAPE & Coefficient of Correlation, $\mathrm{R}$ \\
\hline Kanombe & 0.573 & 0.7399 \\
Gisenyi & 0.001 & 0.7730 \\
Kamembe & 0.329 & 0.6606 \\
\hline
\end{tabular}

\section{CONCLUSION}

The annual wind power densities for Kigali, Gisenyi, and Kamembe have been determined as $13.7 \mathrm{~W} / \mathrm{m}^{2}, 18.4 \mathrm{~W} / \mathrm{m}^{2}$ and $24.9 \mathrm{~W} / \mathrm{m}^{2}$ respectively, from the yearly mean wind speeds of $2.36 \mathrm{~m} / \mathrm{s}, 2.95 \mathrm{~m} / \mathrm{s}$ and $2.97 \mathrm{~m} / \mathrm{s}$. From the results, it is obvious that Kamembe has the greatest wind power potential of all the three sites studied hence is a promising site for installing a wind turbine for small-scale power generation. Large-scale wind power generation require that mean wind speeds exceed $7 \mathrm{~m} / \mathrm{s}$ to generate at least $200 \mathrm{~W} / \mathrm{m}^{2}$. Using the results, the sites are classified under wind power class 1 since their mean velocities are below the $4.4 \mathrm{~m} / \mathrm{s}$ threshold.

\section{ACKNOWLEDGEMENTS}

The authors are grateful to Meteo Rwanda for providing the wind speed and wind direction data and to SFAR for availing the research funds.

\section{REFERENCES}

Bilgil, M. \& Sahin, B., 2009. Investigation of Wind Energy density in the Southern and South-Western region of Turkey. Journal of Energy Engineering, Volume 12, pp. 12-20.

Carrillo, C., Silva-Ucha, M., Diaz-Dorado, E. \& Perez-Sabin, F., 2010. Performance of a Small Wind energy generator under different configurations and settings. EPE Wind Energy seminar, 15-16 April, pp. 1-10. 
Asia Pacific Journal of Energy and Environment, Volume 1, No 3 (2014)

Carta, J. A., Ramirez, P. \& Velazquez, S., 2009. A Review of Wind speed probability distributions used in Wind Energy analysi: Case studies in the Canary Islands.. Renewable and Sustainable Energy Reviews, Volume 13, pp. 933-955.

Dinler, S. A. A. a. A., 2009. A new method to estimate Weibull parameters for wind Energy Applications. Energy Conversion and management, Volume 50, pp. 1761-1766.

Gong, L. \& Jing, S., 2010. Application of Bayesian model averaging in modelling long-term wind speed distributions. Renewable Energy, Volume 35, pp. 1192-1202.

Gungor, A. \& Eskin, N., 2008. The Characteristics that define Wind as an Energy Source. Energy Sources part (A), Volume 30, pp. 842-855.

Himri, Y., Himri, S. \& A, B. S., 2010. Wind Speed Data Analysis used in Installation of Wind Energy Conversion Systems in Algeria. New Orleans, LA, USA, IEEE.

Ilkilic, C. \& Turkbay, I., 2010. Determination and Utilization of Wind Energy potential for Turkey. Renewable and Sustainable Energy Reviews, Volume 14, pp. 2202-2207.

Islam MA, Bhuiya MA and Islam MS. 2014. A Review on Chemical Synthesis Process of Platinum Nanoparticles Asia Pacific Journal of Energy and Environment, 1, 107-120.

Khan, A. A. \& Shahidehpour, M., 2009. Day Ahead Wind Speed Forecasting using Wavelets. Seattle, WA USA, IEEE.

Ministry of Infrastructure, 2011. [Online] Available at: http://mininfra.gov.rw/ [Accessed 20 January 2014].

Safari, B., 2010. A review of Energy in Rwanda. Renewable and Sustainable Energy reviews, Volume 14, pp. 524-529.

Seyit, A. A., Bagiorgas, H. S. \& Mihalakakou, G., 2010. Use of two-component Weibull mixtures in the analysis of wind speed in the Eastern mediterranean. Applied Energy, Volume 87, pp. 2566-2573.

Wikipedia, n.d. Rwanda. [Online] Available at: http://en.wikipedia.org/wiki/Rwanda [Accessed 3 August 2014].

Yohana, N. M., Sungsu, L. \& Young-Kyu, L., 2009. Topographical Effects on Wind Speed over various terrains: A Case Study for Korean Peninsula. The Seventh Asia-Pacific Conference on Wind Engineering, 8-12 November.

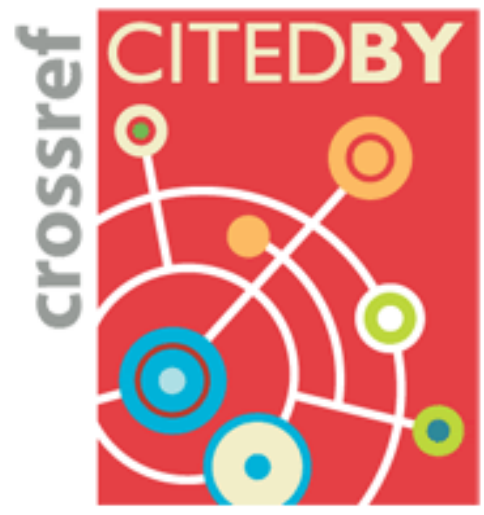




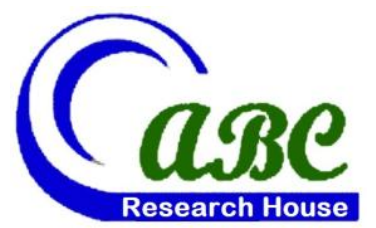

- Off Pantai Dalam, Kuala Lampur, Malaysia

- Rd 4, Shyamoli, Dhaka-1207, Bangladesh

- 3900 Woodhue Place, Alexandria, VA 22309, USA

www.abcreorg.weebly.com / www.abcjournals.net

Asian Business Consortium (ABC) is a multi-disciplinary research, training, publishing, digital library supporting and service house. Though founded in 2010 as the Business and Computing organization of Asia, it was reconstituted as the ABC in 2011. It has been working for creating and nurturing talents in USA, Malaysia and Bangladesh since its inception. As ABC is going global, it intends to open chapters in Australia, Germany, Japan, Pakistan, and other Asian countries in near future. The objectives of consortium are solely centered round the welfare and humane attitude of the founders who enthusiastically took up this noble cause and materialized it with a view to promote research and educational activities for the encouragement of scholars to develop their knowledge, to publish their analysis oriented scientific researches in international Journals, books, the task of organizing workshops, seminars, conferences, training, personality development programs and allied services.

In addition to research activities, ABC provides a good number of scholarships to the poor and meritorious students at various levels of education throughout the world. It plays an important role in the field of research by funding research projects and publishing the research papers. This consortium will unquestionably become the mouth-piece of the dark horses and unacknowledged scholar whose endowed and commendable contributions shall be provided an outlet keeping in mind the greater good of the larger society of the world.

$\mathrm{ABC}$ runs the following international referred journals for creating a platform to share the thoughts of professionals, scholars and academicians throughout the world.

\section{ABC Publications (ABC Journals)}

- Asian Accounting and Auditing Advancement (4A Journal)

- Asian Business Review (ABR)

- $\quad$ Asian Journal of Applied Sciences and Engineering (AJASE)

- Global Disclosure of Economics and Business (GDEB)

- $\quad$ ABC Journal of Advanced Research (ABC-JAR)

- International Journal of Reciprocal Symmetry and Theoretical Physics (IJRSTP)

- American Journal of Trade and Policy (AJTP)

- Asian Journal of Humanity, Art and Literature (AJHAL)

- Malaysian Journal of Medical and Biological Research (MJMBR)

- Asia Pacific Journal of Energy and Environment (APJEE)

- Engineering International (EI)

- $\quad$ ABC Research Alert (Online)

Each journal home page provides specific information for potential authors and subscribers. Open access policy, the quick review process, rich editorial boards and quality publications have already made $A B C$ Journals unique. ABC Journals are published under the direct supervisions of renowned academicians of the world.

Collaboration in Conference: $\mathrm{ABC}$ considers high-quality conference papers for publication. Please contact us for detailed information.

Collaboration in Publishing: If you like to start writing a book, propose a new journal or advertise in $\mathrm{ABC}$ journals, please feel free to contact us. 